\title{
Stability improvement of an ATV by modifying Suspension Parameters
}

\author{
Bharathi Mohan $\mathrm{M} \mathrm{P}^{1}$, Arjungopal $\mathrm{M}^{2}$, Manoj $\mathrm{S}^{3}$, Dr. S. Neelakrishnan ${ }^{4}$ \\ ${ }^{1}$ (Assistant Professor, Department of Automobile Engineering, PSG College of Technology, Coimbatore-04 \\ ${ }^{2}$ (Department of Automobile Engineering, PSG College of Technology, Coimbatore-04 \\ 3 (Department of Automobile Engineering, PSG College of Technology, Coimbatore-04 \\ ${ }^{4}$ (Professor and Head, Department of Automobile Engineering, PSG College of Technology, Coimbatore-04
}

\section{ABSTRACT}

Suspension design of an ATV is presented. At present, the vehicle is equipped with Parallel Short Long Arm at front and 3 Link Trailing Arm at the rear. As present vehicle's stability is low, modifications are made to the design. The stability of an ATV majorly depends on the Suspension system. By modifying the rear suspension design and also by reducing the un-sprung mass, stability is greatly improved. The modifications are done by considering other dynamic parameters. The main objective was to make the vehicle controllably oversteer. Rear $\mathrm{H}$-Arm with single camber link is selected as it has minimal members and the geometry reduces the rear roll center position which greatly improves stability.

Keywords-Baja suspension system, H-Arm, independent suspension, parallel short long arm.

\section{INTRODUCTION}

SAE Baja is a student engineering challenge where undergraduatestudents design, fabricate and test ATVs. The vehicle that was fabricated for the last event won many awards. But it had its own limitations. The vehicle had stability issues. The stability of the vehicle can be improved by reducing the un-sprung mass. By reducing the un-sprung mass, the work-done by the suspension system is greatly reduced. Another important parameter that has to be considered while designing the suspension system of an ATV is that the vehicle is made to oversteer which in turn helps better control during corners. The design is focused to make the vehicle oversteer by using three-wheel cornering technique as the spool setup is used in the rear instead of differential.

\subsection{FUNCTIONALITY OF SUSPENSION SYSTEM}

1. To maintain road to wheel contact under all conditions.

2. To minimize road shocks from transmitting to the driver.

\subsection{OBJECTIVES CONSIDERED FOR DESIGNING THE} SUSPENSION SYSTEM

1. To maintain road to wheel contact

2. Avoid rollover of the vehicle

3. Increase ground clearance

4. Oversteer the vehicle

5. Increase wheel travel

6. Reduce un-sprung mass

\subsection{SELECTION OF SUSPENSION GEOMETRY}

Independent suspension system is selected because of its advantage over dependent suspension setup. The front suspension geometry was selected as parallel short long arm. Parallel SLA which are nearly parallel to the ground have lower roll center position. It also has camber gain during cornering that facilitates good road contact during tight turns. The rear suspension geometry is H-Arm with single camber link. This setup is similar to Parallel wishbone but having modified lower control arm and a single camber ink.

The material of choice was AISI 4130 as it has good strength to weight ratio as compared to other steel. The cross section of the front control arms is 0.75 " $\mathrm{x} 0.035$ " and that of rear arms are $1 " \times 0.035$ ".

\subsection{DeSign PARAMETERS CONSIDERED}

The suspension system of an ATV need to satisfy a number of requirements whose aim mainly conflicts because of different operating conditions.

\subsubsection{Camber}

Both positive and negative camber provides uneven tire wear. But while negotiating a curve in the outer wheel will experience a positive camber due to lateral force that can be compensated by providing a slight negative camber (close to zero). Negative camber gain on inner wheels and positive camber gains on outer wheel will ease the cornering at high speeds. 


\subsubsection{Castor}

Providing positive castor allows selfcentering of the steering wheels. Providing a negative castor will harden the steering. $10^{\circ}$ castor angle with respect to the amount of camber gain required while cornering is set.

\subsubsection{Roll Stiffness}

Roll stiffness is the resistance offered by the roll cage to the roll of the sprung mass due to cornering force.Roll stiffness offers a better load transfer between axles and in lateral direction. Roll stiffness are influenced by left and right wheels' suspension stiffness.

\subsubsection{Roll Gradient}

Roll gradient is the roll per degree of $g$ of lateral force. Roll gradient depends on the distance between front and rear roll centers from the CG. Higher the roll stiffness, higher the roll gradient.

\subsection{SPRING AND DAMPER SELECTION}

Coil spring provides a constant stiffness that cannot be varied, mounting is difficult, and increases the un-sprung mass, but in case of air shocks it has an infinite range of the stiffness to vary, light weight and easy to mount. Roll gradient is the roll per degree of $\mathrm{g}$ of lateral force. Roll gradient depends on the distance between front and rear roll centers from the CG. Higher the roll stiffness, higher the roll gradient.

\subsection{Calculations}

As there are rules pertaining to the dimensions of the vehicle, the wheelbase and track was decided based on Baja SAE rule book.

TABLE 1 Vehicle Specifications

\begin{tabular}{|l|l|}
\hline Front Wheel Track $\left(\mathrm{t}_{\mathrm{f}}\right)$ & $1320 \mathrm{~mm}$ \\
\hline Rear Wheel Track $\left(\mathrm{t}_{\mathrm{r}}\right)$ & $1244 \mathrm{~mm}$ \\
\hline Wheel Base $(\mathrm{l})$ & $1574 \mathrm{~mm}$ \\
\hline Motion Ratio $(\mathrm{F} / \mathrm{R})$ & 0.5 \\
\hline Vehicle Weight & $2060.1 \mathrm{~N}$ \\
\hline Droop (F/R) & $150 / 50 \mathrm{~mm}$ \\
\hline Height of CG & $400 \mathrm{~mm}$ \\
\hline $\begin{array}{l}\text { Distance of CG from } \\
\text { front axle }\end{array}$ & $838.2 \mathrm{~mm}$ \\
\hline $\begin{array}{l}\text { Distance of CG from } \\
\text { rear axle }\end{array}$ & $685.8 \mathrm{~mm}$ \\
\hline \multicolumn{2}{|c|}{ Wheel Rate $W_{r}=\frac{\text { Corner Weight }}{\text { Droop }}$} \\
\hline
\end{tabular}

Wheel Rate $W_{r}=\frac{566.527}{50}=11330.5 \mathrm{Nm}^{-1}$ Spring Rate $S_{r}=\frac{\text { Wheel Rate }}{1 /(\mathrm{mr})^{2}}$

Spring Rate $S_{r}=\frac{11330.5}{1 /(0.5)^{2}}=45322.2 \mathrm{Nm}^{-1}$

$$
\begin{array}{r}
\text { Ride Rate } R_{r}=\frac{W_{r}+R_{r}}{W_{r} \times R_{r}} \\
\text { Ride Rate } R_{r}=\frac{11330.5+45322.2}{11330.5 \times 45322.2} \\
=9064.44 \mathrm{Nm}^{+1} \\
\text { Ride Frequency }=\frac{(\mathrm{mr})}{2 \pi} \sqrt{\frac{\mathrm{Sr}}{m}} \\
\text { Ride Frequency }=\frac{(0.5)}{2 \pi} \sqrt{\frac{45322.2}{57.74}}=2.23 \mathrm{~Hz} \\
\text { Roll Stiffness } K_{\theta}=\frac{\pi t^{2} \mathrm{~W}^{2}}{180 \times 2 \times W} \\
\text { Roll Stiffness } K_{\theta}=\frac{\pi \times 1.295^{2} 11330.5^{2}}{180 \times 2 \times 11330.5} \\
=165.73 \mathrm{Nm} / \mathrm{deg} \\
\text { Roll Gradient } \frac{\theta}{A_{y}}=\frac{-W \times H_{r}}{K_{\theta f}+K_{\theta r}} \\
\text { Roll Gradient } \frac{\theta}{A_{y}}=\frac{-2060.1 \times 0.2595 \times 0.55}{50.70 \times 165.73} \\
=1.82 \mathrm{deg} g^{-1}
\end{array}
$$

Lateral Weight Transfer

$$
=\frac{W}{t}\left[\frac{H \times K_{\theta r}}{K_{\theta f}+K_{\theta r}}+\frac{a \text { or } b}{l} \times Z_{r}\right]
$$

Lateral Weight Transfer

$$
\begin{aligned}
& =\frac{2060.1}{1.295}\left[\frac{0.299 \times 165.73}{50.70+165.73}\right. \\
& \left.+\frac{0.210 \times 0.6858}{1.524}\right]=614 \mathrm{~N}
\end{aligned}
$$

\subsection{SUSPENSION COMPONENT DESIGN}

The components were designed using Solidworks 2015. Fig1 shows the completed assembly image of front and rear suspension system. Front control arms were designed considering steering gearbox position and shock position. Rear HArm was designed by considering driveshaft position.

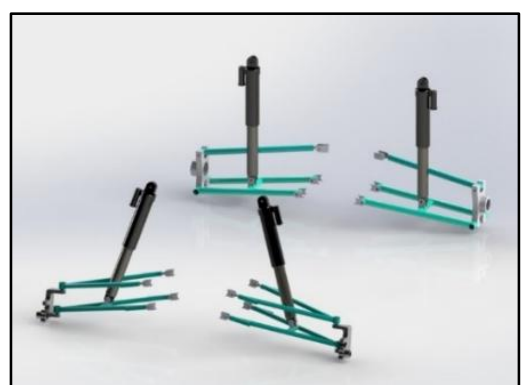

Fig. 1 Front and Rear Suspension Assembly

TABLE 1 Suspension Specification

\begin{tabular}{|l|l|l|}
\hline PARAMETER & FRONT & REAR \\
\hline Geometry & Parallel SLA & $\begin{array}{l}\text { H-Arm } \\
\text { Camber Link }\end{array}$ \\
\hline $\begin{array}{l}\text { Springs and } \\
\text { Dampers }\end{array}$ & $\begin{array}{l}\text { FOX Float 3 } \\
\text { Evol }\end{array}$ & $\begin{array}{l}\text { FOX Float 2 } \\
\text { Evol }\end{array}$ \\
\hline Arm Length & $435 \mathrm{~mm}$ & $437 \mathrm{~mm}$ \\
\hline
\end{tabular}




\begin{tabular}{|l|l|l|}
\hline $\begin{array}{l}\text { Arm to Arm } \\
\text { Length }\end{array}$ & $95 \mathrm{~mm}$ & $95 \mathrm{~mm}$ \\
\hline Castor & $10^{\circ}$ & $0^{\circ}$ \\
\hline Camber & $0^{\circ}$ & $0^{\circ}$ \\
\hline
\end{tabular}

\subsection{ANALYSIS OF SUSPENSION COMPONENTS}

ANSYS Workbench was used to analyze the designed components. The worst-case scenario was assumed to evaluate the strength of the control arms. For the front control arms, the roll cage ends are fixed and load is applied on the spherical bearing cup.

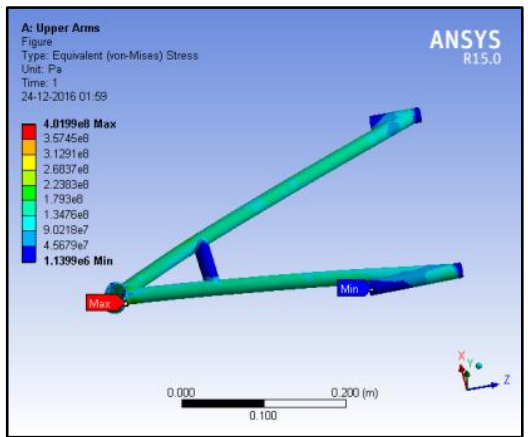

Fig. 2 Analysis of Upper Front Control Arm

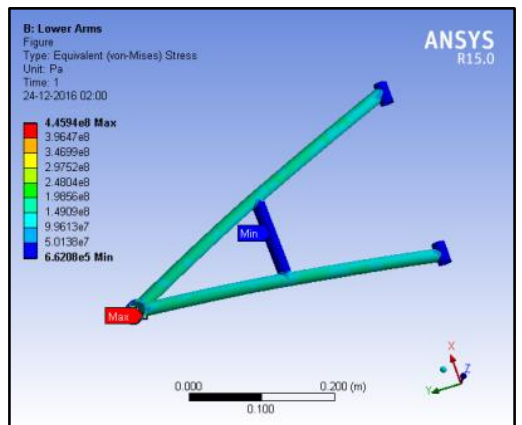

Fig. 3 Analysis of Lower Front Control Arm

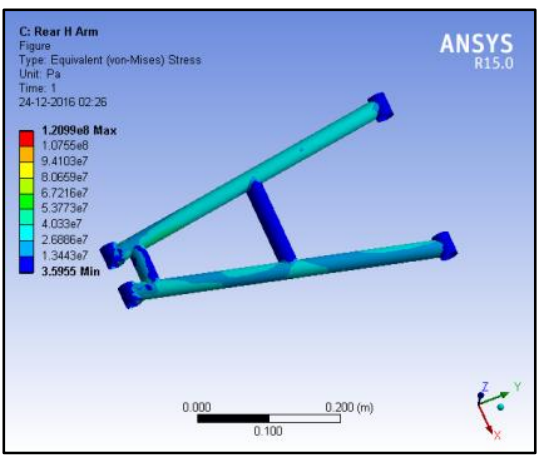

Fig. 4 Rear H-Arm Analysis

Fig. 2 and Fig. 3 shows the analysis of Front upper and lower control arms. The maximum stress acting on them is $401.9 \mathrm{MPa}$ and $445.9 \mathrm{MPa}$. Similarly, Fig. 4 shows the analysis of Rear H-Arm. The maximum stress acting on them is $120.9 \mathrm{MPa}$. This data shows that the stress acting is less than the yield strength of the material and the components are safe.

\subsection{FORWARD SLOPING ROLL AXIS}

The vehicle will over steer if it had a forward sloping roll axis. This is achieved by the inclinations of the control arms. Under static conditions, the front control arms are inclined at an angle of $9^{\circ}$. This shows that the arms are nearly parallel to the ground. By having this setup, the front roll center is made to be near the ground. Similarly, at the rear, the arms are inclined without affecting the working angle of the drive shaft. The roll center position was found to be near the CG. This indicates forward sloping roll axis, which implies oversteer of the vehicle.

\subsection{LOAD TRANSFER}

There are two types of load transfer, the elastic load transfer and geometric load transfer. The former happens due to lateral force acts at the CG of the car, thereby creating a rolling moment whose moment arm is equal to the vertical distance between the roll center and the point where the mass centroid axis of the vehicle intersects the axles. This causes the sprung mass to roll, extending and compressing the inner and outer springs respectively, thereby causing a component of weight transfer that happens through the springs.

Geometric load transfer due to the lateral force acting on the roll center. And hence the moment arm in this case is zero and hence there is no body roll. Increasing the roll center at the rear increases the geometric load transfer and decreases the elastic load transfer. The front of an ATV must experience more elastic load transfer, whereas the rear must experience more geometric load transfer.

This helps in sending the weight from the inner to the outer wheels quicker.This reduces the traction at the rear axle substantially. This calls for higher slip angle at rear causing the ATV to oversteer.

Oversteer is also obtained by lifting the inner rear wheel when encountering a corner. This is obtained by increasing the load transfer in the rear by reducing the wheel track in the rear than in the front. Having stiffer suspension will reduce the droop

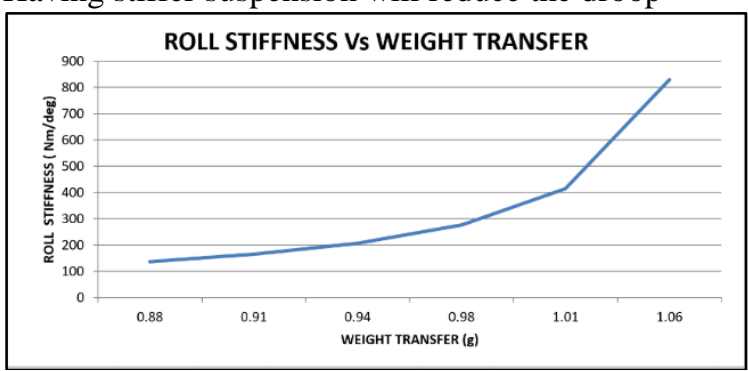

Fig. 5 Roll Stiffness vs. Weight Transfer 


\subsection{SUSPENSION ANALYSIS USING LOTUS SHARK}

Lotus Shark is used to study the dynamic behavior of the suspension assembly. The front and rear control arms are modeled. The hard points are obtained from the assembly.

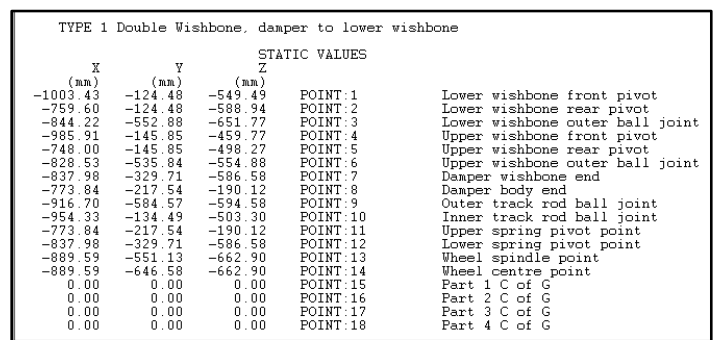

Fig. 6 Front Suspension Assembly - Hard Points

The Fig.6 and Fig 7 shows the obtained Hard Points from CAD model. These points are then exported to Lotus Shark.

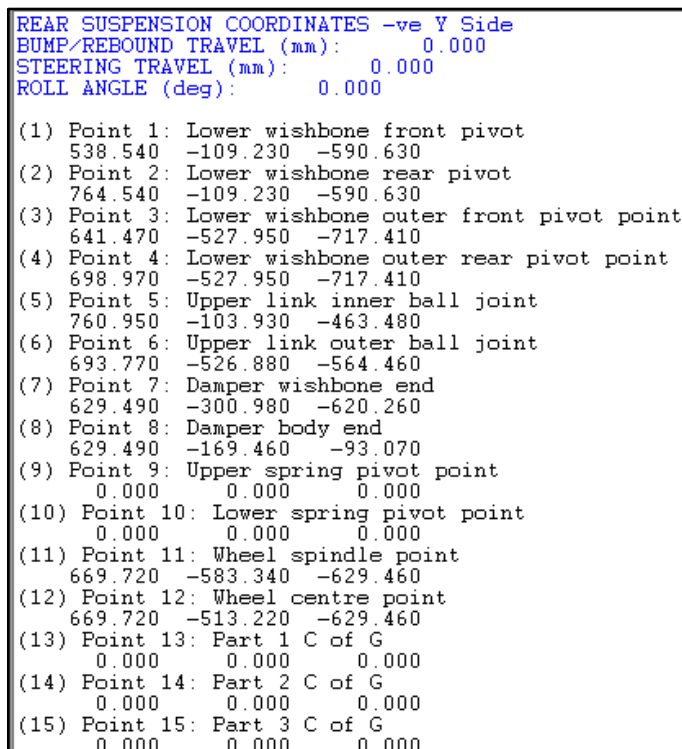

Fig. 7 Rear Suspension Assembly - Hard Points

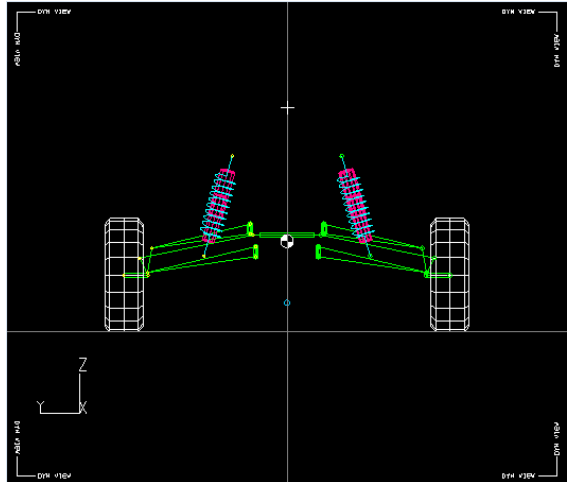

Fig. 8 Front Suspension - Lotus Shark

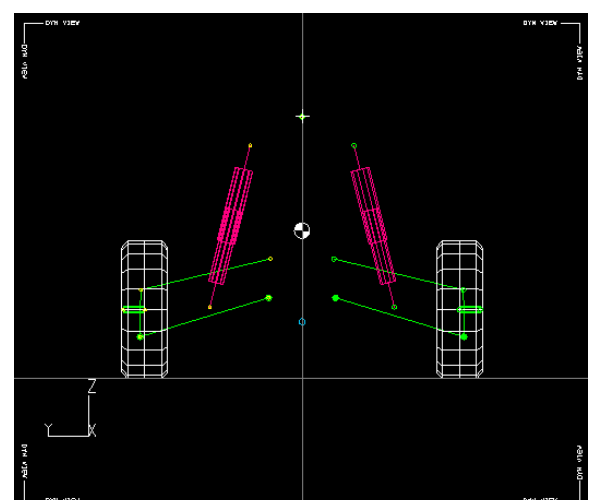

Fig. 9 Rear Suspension -Lotus Shark

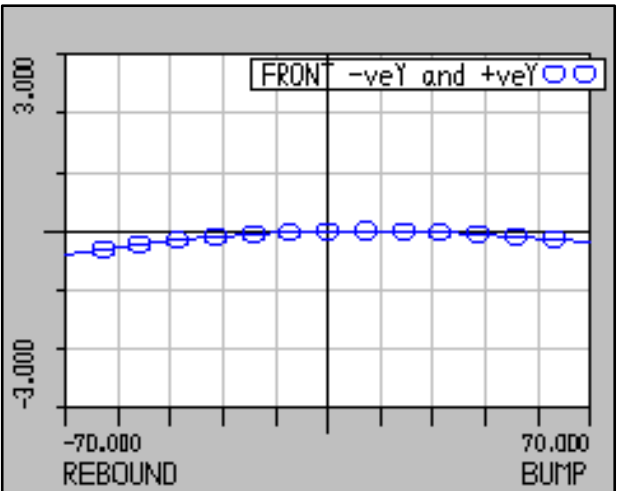

Fig. 10 Front - Wheel Travel vs Camber Change

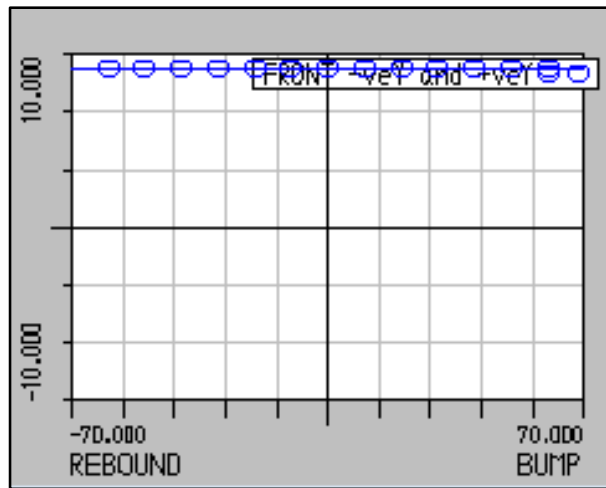

Fig. 11 Front - Wheel Travel vs Castor Change

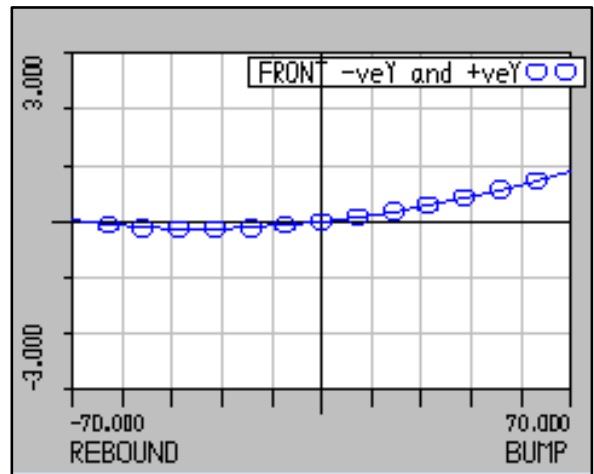

Fig. 12 Front - Wheel Travel vs Toe Change 
The Fig 10, Fig 11 and Fig 12 show that there is only minimum change is Camber, Toe and Castor during wheel travel. This proves that the road wheel contact will be maintained in all cases.

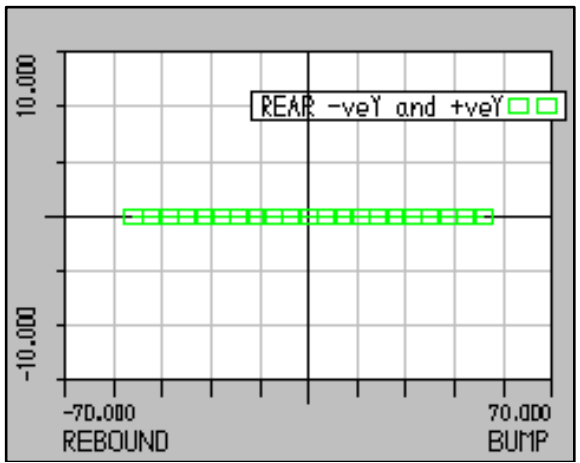

Fig. 13 Rear - Wheel Travel vs Castor Change

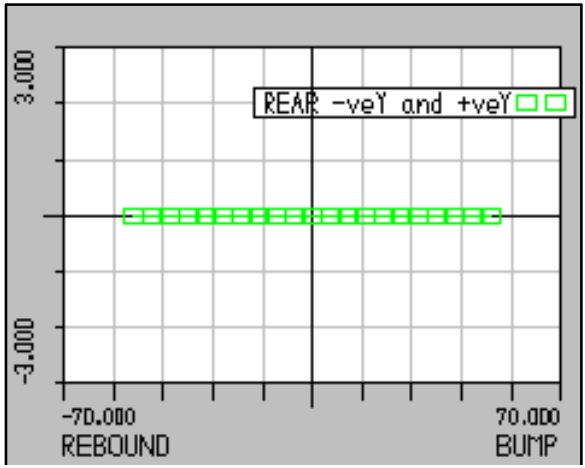

Fig. 14 Rear - Wheel Travel vs Toe Change

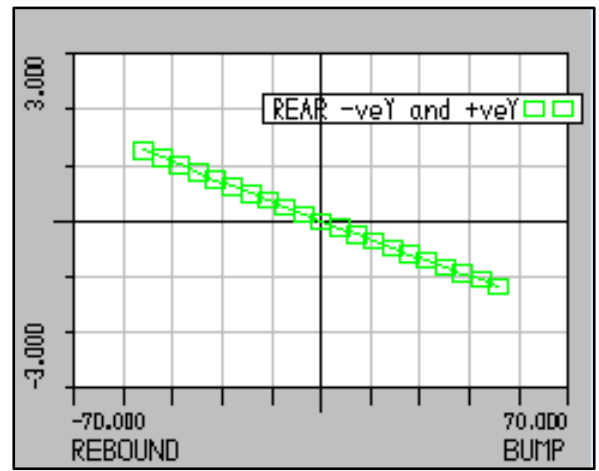

Fig. 15 Rear - Wheel Travel vs Camber Change

The Fig 13, Fig 14 and Fig 15 show that there is only minimum change is Camber, Toe and Castor during wheel travel. This proves that the road wheel contact will be maintained in all cases.

\section{CONCLUSION}

By modifying the suspension parameters, the dynamic behavior of the ATV is modified in favor of the driver. The controllable oversteer helps the driver during tight corners. As the un-sprung mass is reduced the work done by the suspension system is reduced. This improves the stability of the vehicle. The limitation in going for this type of suspension system reduces the possibility of threewheel cornering. If the vehicle had three-wheel cornering, there was a possibility of roll over as stability is reduced. This suspension setup also reduces the time for assembly, hence time for servicing is reduced.

\section{REFERENCES}

[1]. Jagirdar, V.V., Pandurengan, D., "Development of Double wishbone independent suspension system for a military truck", Symposium on International Automotive Technology SIAT-2009 Reference Technical Bulletin.

[2]. Milliken, Douglas L., and William F. Milliken. Race Car Vehicle Dynamics. Warrendale: Society of Automotive Engineers (SAE), 1995. Print.

[3]. Gillespie, T. D. Fundamentals of Vehicle Dynamics. Warrendale, PA: Society of Automotive Engineers, 1992. Print.

[4]. Dixon, John C. Tires, Suspension, and Handling. Warrendale, PA: Society of Automotive Engineers, 1996. Print.

[5]. Smith, Carroll. Tune to Win. Fallbrook, CA: Aero, 1978. Print.

[6]. Timoney, E.P., Timoney, S.S., Timoney, S.G., "Heavy vehicle independent suspension", Proceedings of the IMechE, "Advanced suspensions", C434/88, 1988-9, PP 125-133.

[7]. Dr. Kirpal Singh, "Automobile Engineering” Vol. I, Standard Publishers Distributors. 13th Edition, 2013, PP 70-219.

[8]. R.B. Gupta, "Automobile Engineering" Satya Prakashan, Ninth Edition, 2014, PP 32-3 - 34-21.

[9]. B. Bhandari, "Design of Machine Elements" The McGraw-Hill Companies, Second Edition, 2008, PP 389- 435.

[10]. Xintian Liu, Jiao Luo, Yansong Wang, Hui Guo and Xinyu Wang, "Analysis for Suspension Hardpoint of Formula SAE Car Based on Correlation Theory", Research Journal of Applied Sciences, Engineering and Technology 6(24): 4569-4574, 2013, PP 4569-4574

[11]. Prior, Gary M., "The use of multi-body systems analysis in the design and analysis of vehicle suspension systems", SAE 921463, 1992. 